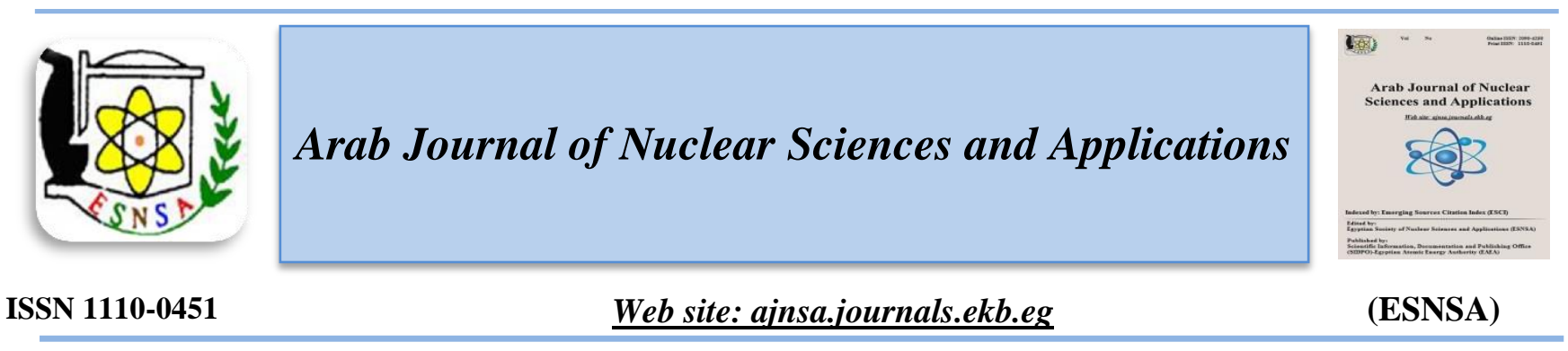

\title{
The Reactor Power Effect on the consequences Pressure Waves after LBLOCA in VVER-1000
}

\author{
Dina Ali Amer, Nikonov Sergey Pavlovich \\ National Research Nuclear University “MEPhI”, Moscow, Russia
}

\begin{abstract}
Received 14 Apr. 2020 In this paper, the influence of the reactor power on the LBLOCA hydrodynamics at the initial stage of Accepted 29 Nov. 2020 the process (0-1 second) is considered. The calculations are carried out for the first loop in case of the beginning of loading, end of loading and constant power level. The strongest amplitude and frequency of pressure wave's fluctuations in NPP elements occurred during the first seconds of accident initiation. Thus, in the present work the analysis is focused on this period. These pressure fluctuations can lead to significant dynamic loads on the structural elements of the NPP. The parameters of a typical reactor plant V-320 (VVER-1000) were used in the calculation, particularly, the $3^{\text {rd }}$ unit of the Kalinin NPP.
\end{abstract}

Keywords: VVER-1000, LOCA, Kalinin-3, MCP stop, LOCA, ATHLET

Symbols and Abbreviations

\begin{tabular}{|l|l|}
\hline LBLOCA & Large Break loss-of-coolant accident \\
\hline BED & Double End Break \\
\hline DBLOCA & Double ended Break Loss-of-coolant accident \\
\hline ATHLET & Analysis of Thermal Hydraulics of LEaks and Transients (code name) \\
\hline VVER & water-water energetic reactor \\
\hline MCP & main circulation pump \\
\hline TFD & thermal hydraulic module \\
\hline HECU & heat exchange and thermal conductivity module \\
\hline NEUKIN & neutron-kinetics module \\
\hline GCSM & module to describe the operation of the equipment \\
\hline FEBE & fully implicit module for numerical integration \\
\hline V-UP4 & The output of the reactor mixing chamber \\
\hline V-DC0 & The input of the reactor mixing chamber \\
\hline P1-CL & Cold leg of the first loop \\
\hline P1-HL & Hot leg of the First loop \\
\hline
\end{tabular}

Corresponding author: engineer_dinaali_2009@yahoo.com

DOI: 10.21608/ajnsa.2020.27905.1346

CScientific Information, Documentation and Publishing Office (SIDPO)-EAEA 


\section{Introduction}

Consideration of an emergency situation caused by an instantaneous guillotine rupture of the main circulation pipeline followed by a two-way expiration of the coolant (DBLOCA) for the VVER-1000 reactor plant is mandatory for all documents related to the justification of reactor safety and is regulated by special requirements [1]. In previous studies [2-5] the initial stage of the accident with DBLOCA, the first two seconds of the process, which is characterized by the occurrence of pressure waves in the system, was studied. Ruptures in different places of the main circulation pipeline from the inlet to the outlet of the reactor were analyzed [3]. The effect of the time to complete rupture, on the calculation results of the initial DBLOCA period was shown in an earlier publication [6]. The influence of the main circulation pump (MCP) coast down time on the behavior of pressure waves, was previously studied at the "instantaneous $10^{-4}$ seconds" stop of MCP $[7,8]$. The calculations were carried out using point kinetic model, each of the seven selected reactor zones corresponded to a heat-generating element with an averaged energy obtained from the experimental transient state of the core of the standard problem Kalinin-3

All initial data for the calculations were obtained from the materials of the international standard problem Kalinin-3 [9]. The fuel composition and kinetics parameters of the reactor core were considered for the case of the end of the cycle. For the calculations, the computational best estimate code ATHLET [10.11] was used, which is included in the software package $\mathrm{AC}^{2}$ and officially acquired by the National Research Nuclear University MEPhI according to the license agreement with Gesellschaft fur Anlagen-und Reaktorsicherheit (GRS) gg GmbH, Germany [11]. ATHLET Code is certified in Russia for stationary and transient conditions at reactors with water coolant [12].

\section{A Brief Description of the Calculation Code" ATHLET"}

ATHLET is a thermos-hydraulic code (Analysis of Thermal hydraulics of Leaks and Transitions) which was originally deliberated for the analysis of the entire spectrum of the leak and transient analyses in PWR and BWR reactors. Operating experience has shown that ATHLET code can be successfully applied for Russian reactors such as VVER and RBMK. The ATHLET code consists of several basic modules that allow describing different phenomena in the behavior of the thermal hydraulic systems: thermal hydraulic module (TFD), heat exchange and thermal conductivity module (HECU), neutron-kinetics module (NEUKIN) to describe point and one-dimensional kinetics, module to describe the operation of the equipment (GCSM) and fully implicit module for numerical integration (FEBE). Other independent modules can also be connected via the main interface. Information about the ATHLET code is reported in its manual [10].

Recent studies [5-8] considered the widely used capabilities of the ATHLET code for linking with various three-dimensional neutron- physical programs in the calculations of the spatial distribution of energy release fields and the spatial distribution of the coolant parameters in the reactor core (up to the sub-assembly).

\section{Modeling and-Design Scheme of the Simulated Power Plant}

Figure (1) shows the modeling of the first circuit in the primary coolant loop, which is similar to other three circuits, except considering the double-ended break (DEB) in this first circuit. The design scheme of the plant simulation presented below (Fig. 2) can be correlated to a group of schemes for the analysis of the behavior of a reactor of VVER1000 type (model 320), which were developed for the ATHLET code. The detailed description of the simulated power plant-is included in a previous study [8]. In addition, the scheme of splitting the reactor vessel (Fig. 3) is used as an emergency loop when considering these transients. The scheme of splitting the first loop of the primary cooling circuit from the output (V-UP4) of the mixing chamber and to the input (V-DC0) of the reactor mixing chamber.

- In Figure (2) at the upper left side there is a cross-cutting section at the level of nozzles.

- In the Bottom left side, the core partitioning scheme is explained by seven groups of parallel hydraulic channels (six peripheral ones and a central one).

-In the right side, a cross-section of in-core area Is presented for the reactor of Unit 3, Kalinin NPP. 


\section{The Research Steps and the Three cases Considered in the Current Step}

As mentioned before, the calculations are carried out for the first loop in case of the beginning of loading ("beginning of loading" is the beginning of the fuel cycle), end of loading and constant operating power. The consequences on pressure drop in the main components due to the DEBLOCA in the cold leg near to reactor vessel inlet are compared.

This study presents a part of a 7-step research work. The first step was an analysis for emergency The second step was the detailed explanation of the pressure waves after LOCA (DEB) in Location "L1" leading to the conclusion that the basic reason for the pressure waves is the instantaneous boiling (Flash Evaporation ) of the coolant due to sudden depressurization [2].

The third step was a comparison between the two previous situations [13]. The general conclusion was that the worst situation is recorded in the case of DEB.

Subsequently, the fourth step presented different calculations for different periods of time up to complete rupture $(10 \mathrm{E}-4,10 \mathrm{E}-3,10 \mathrm{E}-2,10 \mathrm{E}-1$ and 1 second) were considered for both emergency cases[6]. The gap-of time- is considered the time of initialization of the emergency process, i.e. the time of rupture when analyzing a double leak and the time of reducing the pump speed to zero when analyzing its stop (blocking). The instantaneous value of the time interval was discussed in a previous publication[1], but without revealing the meaning of the word "instantaneous" in numerical terms, so the study was conducted on the influence of the time gap on the process in the initial period (up to 2 seconds for DEBLOCA \}

As a result, a time gap of 1E-4 second will be considered as the worst case scenario because of the consequences of pressure wave values in each of the main components. Then, the fifth step of this research was published another investigation [3], including a study of 6 different location for DEBLOCA in first loop (Figure 4), which are:

1) In cold leg, entrance of the reactor

2) In the hot leg, exit of the reactor

3) Before MCP

4) After MCP

5) In the hot leg, entrance of the steam generator (hot collector) situations after instantaneous stop of the MCP in the first loop of the primary coolant circuit, [8] and the conclusions were as_follows: The instant stop of the main circulation pump (MCP) caused a pressure waves in reactor core, steam generator (SG), and MCP. Also, the initial period of the accident was considered, since within this time period the strongest amplitude and frequency of pressure fluctuations on NPP elements were observed, which can lead to significant dynamic loads on the structural elements of these objects. Moreover, it is necessary to consider consequent stop of all other MCPs.

6) In the exit of the steam generator (cold collector)

The objective was conducting a comparison between the resulting pressure waves for each break location in the most important points throughout the coolant loop.

Then, the sixth step was about considering the same simulated emergency situations scenario performed for the 6 locations and in each of the 4 loops. The complete analysis for the consequences was performed including the pressure in each point in the four loops, the results were published earlier [5]

In the current step, (the seventh) the influence of the reactor operating power on the system hydrodynamics behavior in case of the LBLOCA at L1 (Figure 3) at the initial moment of the process $(0-1$ second) is considered. Thus, three different states of operation were taken into account:

1- The beginning of loading,

2- The end of loading, and

3- The constant power operation (this means that the feedback effects on the neutron kinetics behavior were not taken into account in the calculations)

The difference between the three cases is in the values of neutron kinetics model data. In each case (the beginning and end of loading), six groups of delayed neutrons are considered. Table (1) shows the values used for each of the six groups and the total percentage (at the end of the Table) 


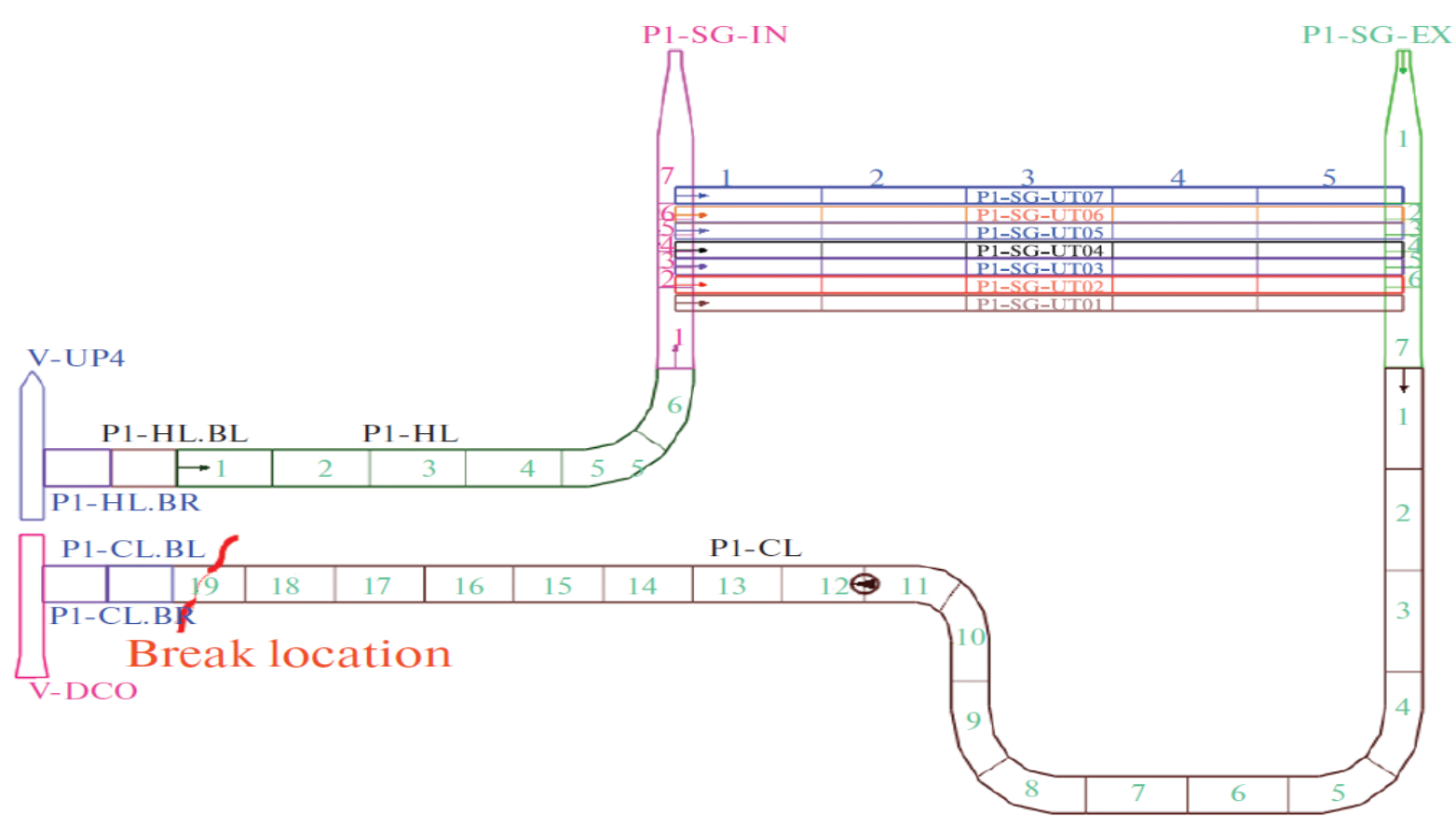

Fig. (1): The scheme of splitting the first circuit in the primary loop
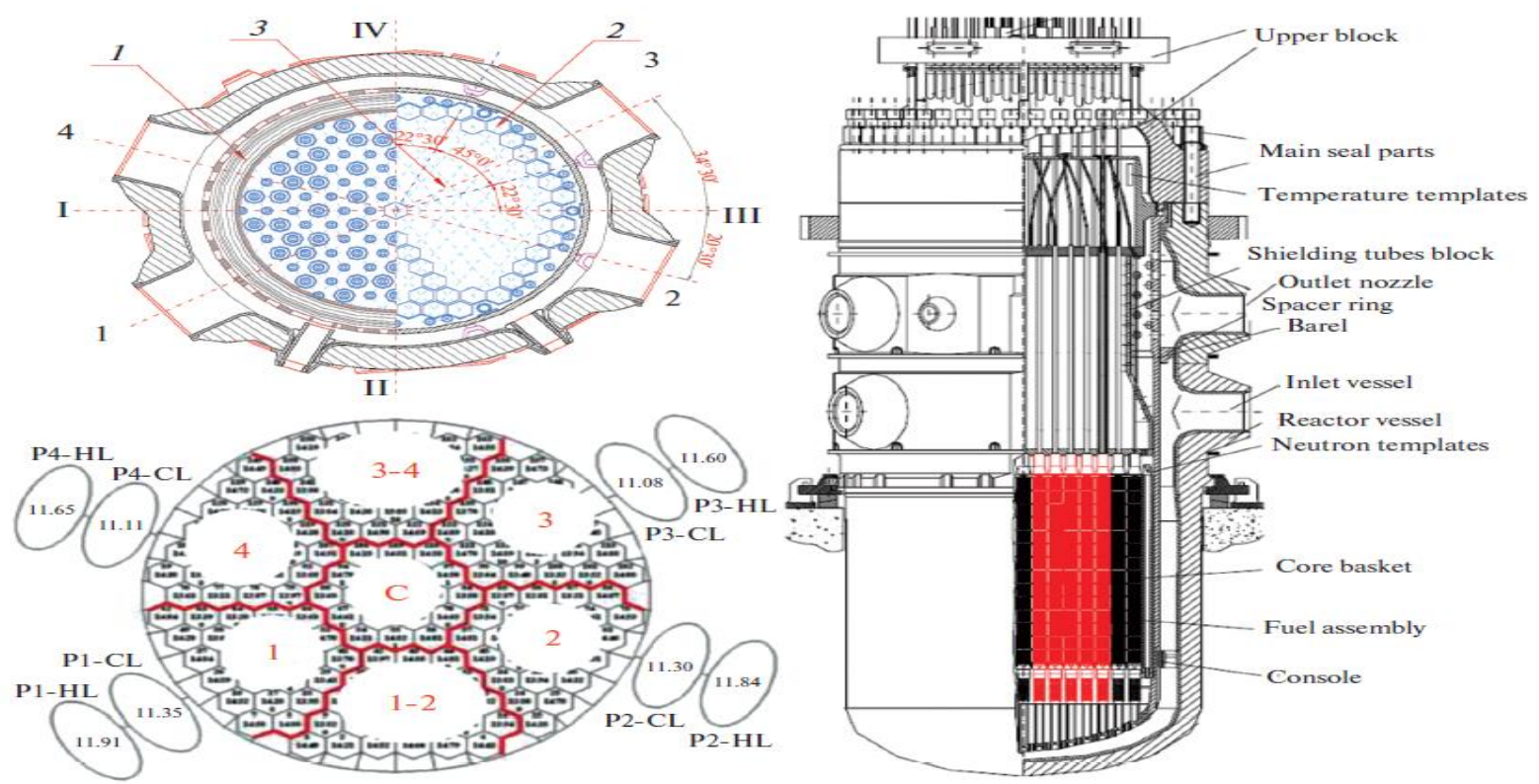

Fig. (2): Reactor Pressure Vessel 


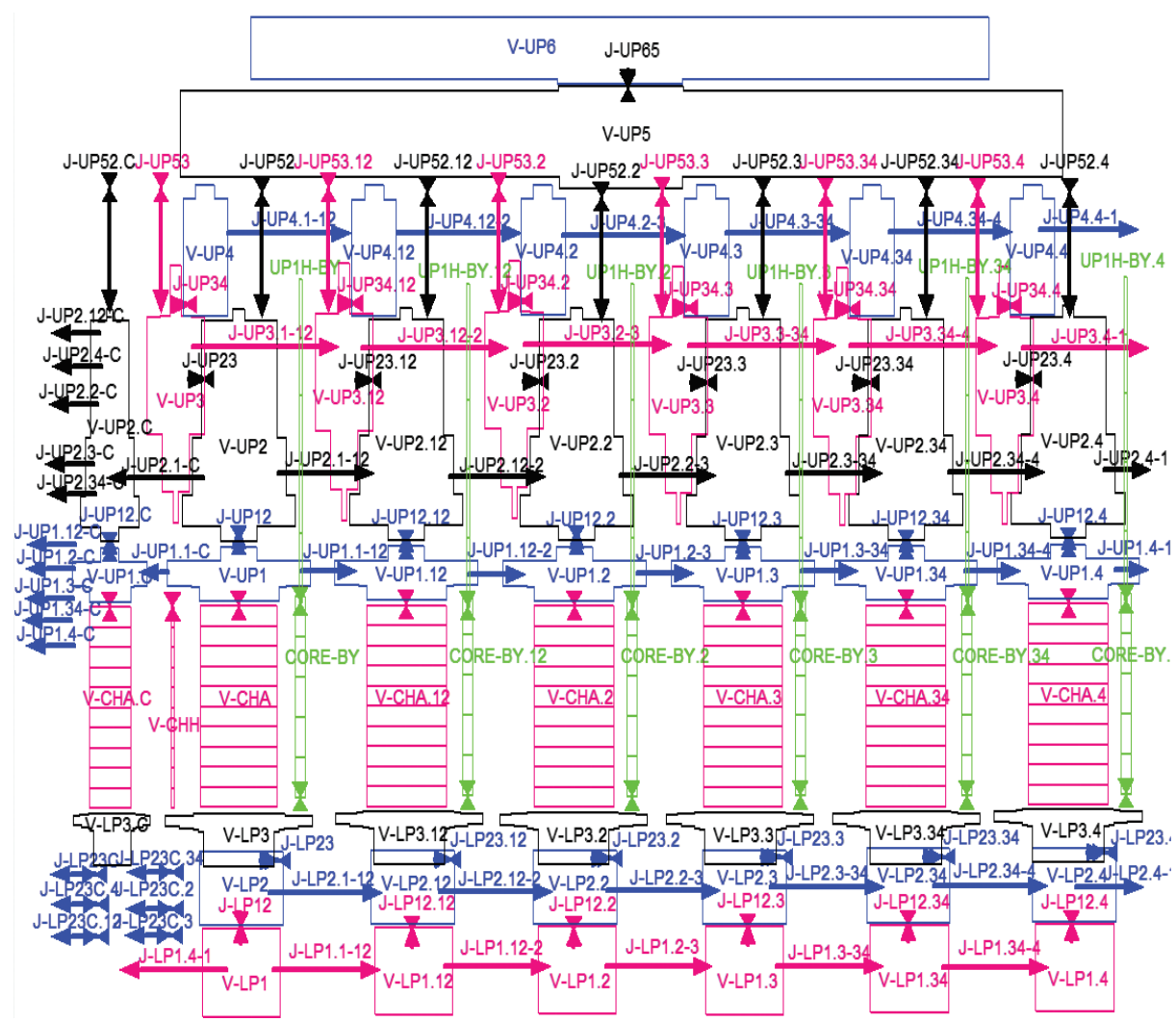

Fig. (3): Nodalization scheme of reactor vessel objects in the primary circuit

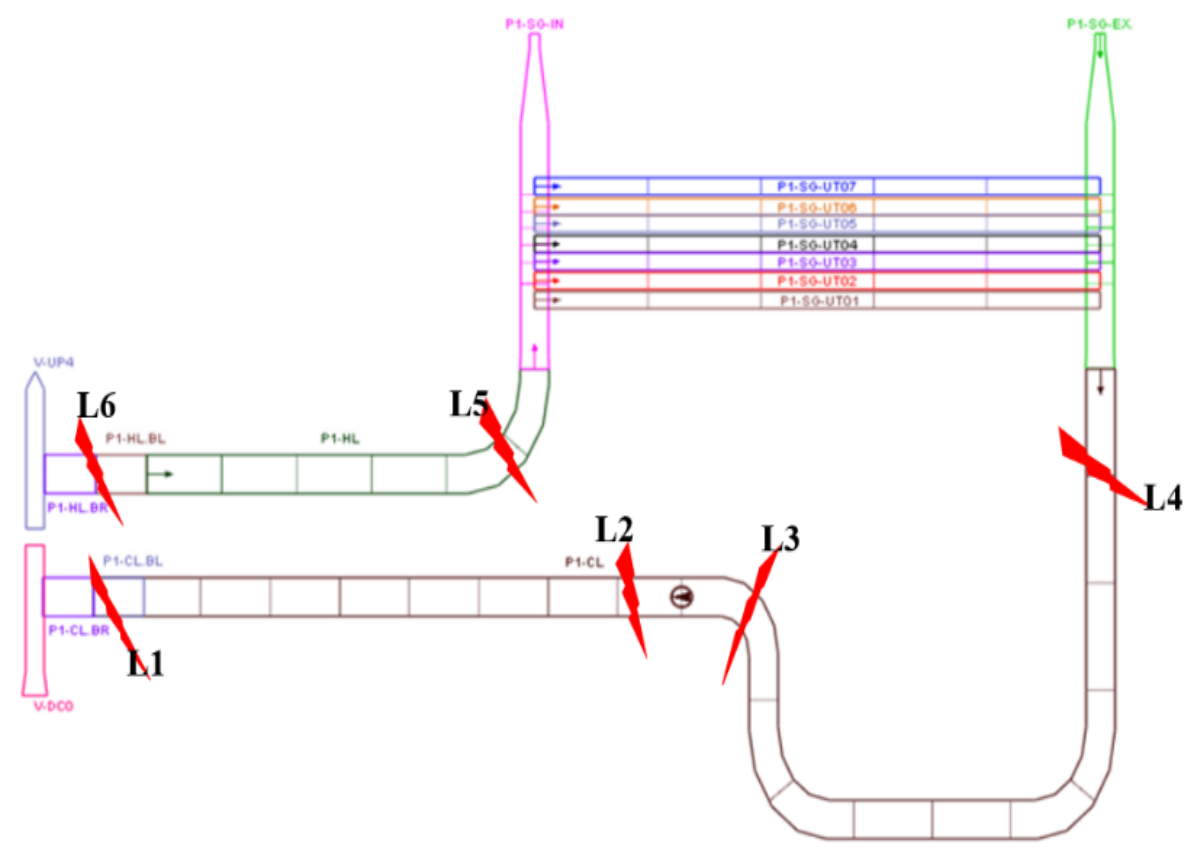

Fig. (4): Considered DELBLOCA locations 
Table (1): Effective 6 groups delayed neutron fractions as well as total fraction in both the beginning and end of fuel loading [14-16]

\begin{tabular}{ccc}
\hline & Beginning of loading & End of loading \\
\hline$\beta 1$ & $0.019 \mathrm{E}-2$ & $0.017 \mathrm{E}-2$ \\
$\beta 3$ & $0.110 \mathrm{E}-2$ & $0.099 \mathrm{E}-2$ \\
$\beta 4$ & $0.104 \mathrm{E}-2$ & $0.091 \mathrm{E}-2$ \\
$\beta 5$ & $0.240 \mathrm{E}-2$ & $0.209 \mathrm{E}-2$ \\
$\beta 6$ & $0.113 \mathrm{E}-2$ & $0.103 \mathrm{E}-2$ \\
$\beta$ & $0.044 \mathrm{E}-2$ & $0.041 \mathrm{E}-2$ \\
\hline
\end{tabular}

\section{Results and Discussions}

A study of DEBLOCA in different locations in the primary cooling circuit of VVER-1000 has been made. The beginning and end of loading were considered. Pressure waves in all points of the primary circuit were noticed in the first seconds of the accident initiation.

To study the effect of the core operating conditions (power and loading) on the plant state (pressure waves), calculation results are displayed in Figures (5 - 9).

- Figure (5) displays thermal power variation with time in the three considered cases.

- Figure (6) shows the changes in pressure drop across the main circulation pump in the first loop 'MCP.1'. The pressure drops varies exactly in the same way for the three cases of study.
- Also, for the reactor pressure variation with time, which is shown in Figure 7, the drop in the pressure and the resulting pressure waves are exactly the same regardless of the operating power or the loading of the reactor core.

- Moreover, the reactor core pressure drops during the first second after the emergency in the three cases of study, is shown in Figure (8). The pressure waves are identical up to 0.3 second, then, after this the pressure waves are continuous but shifted in peaks up to 1 second.

- The steam generator is the last main component of the reactor system considered in this study. The pressure difference in the side of the primary circuit tubes is presented in Figure (9). Also, it can be noticed that the pressure waves are exactly the same in the three cases of study. 


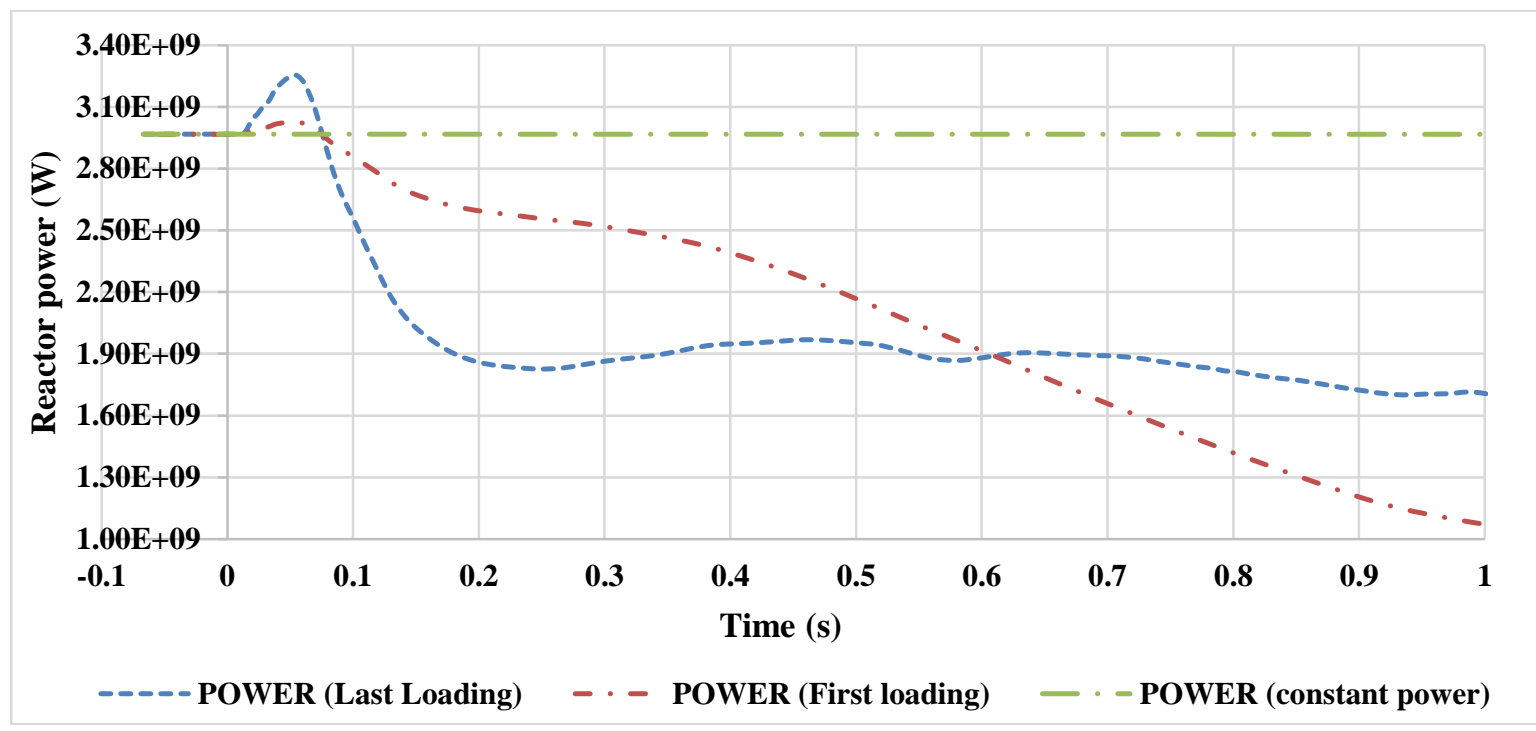

Fig. (5): The variation of thermal power with time in the three considered cases

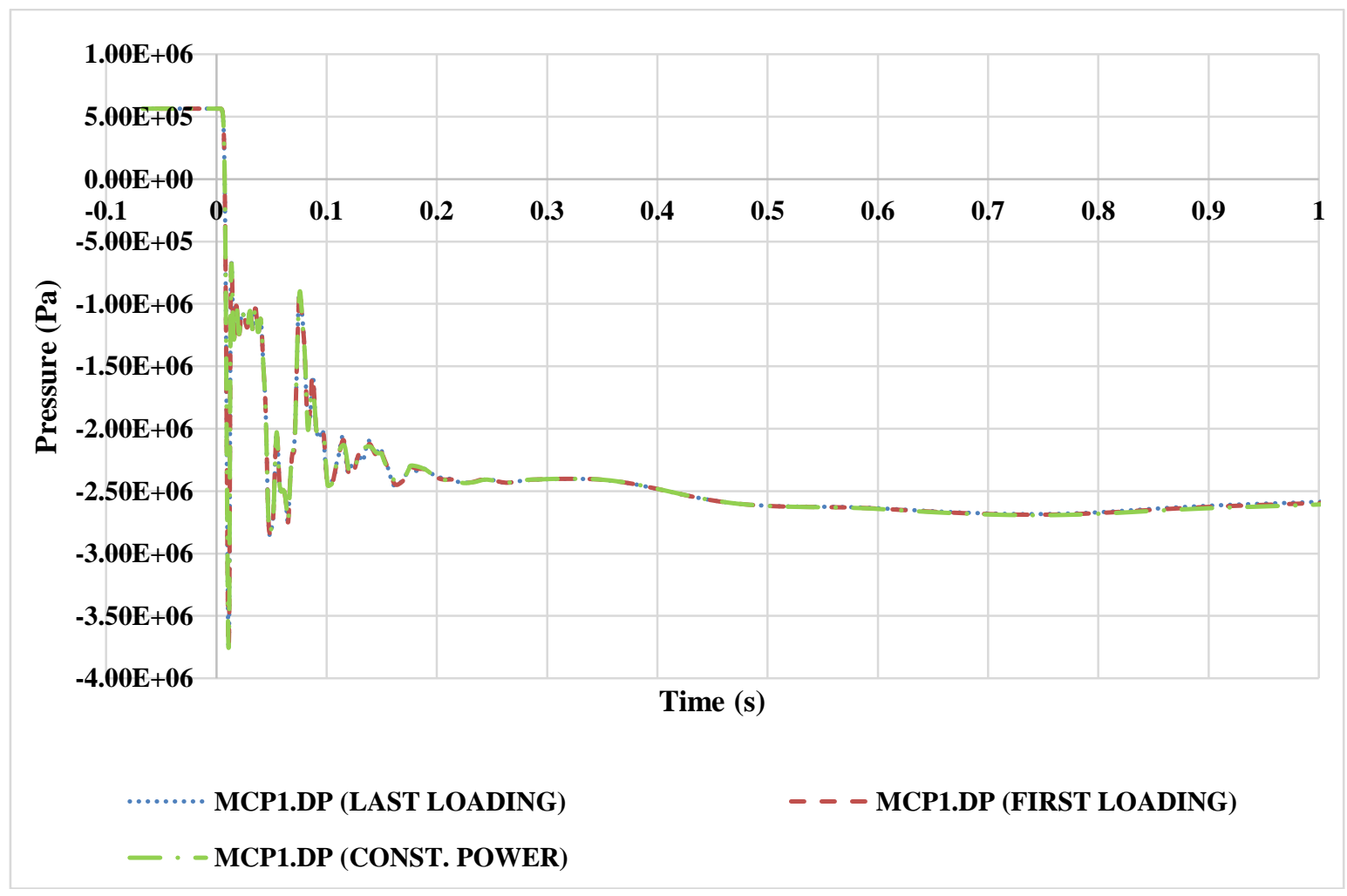

Fig. (6): Pressure drop in MCP.1 in the three cases of study 


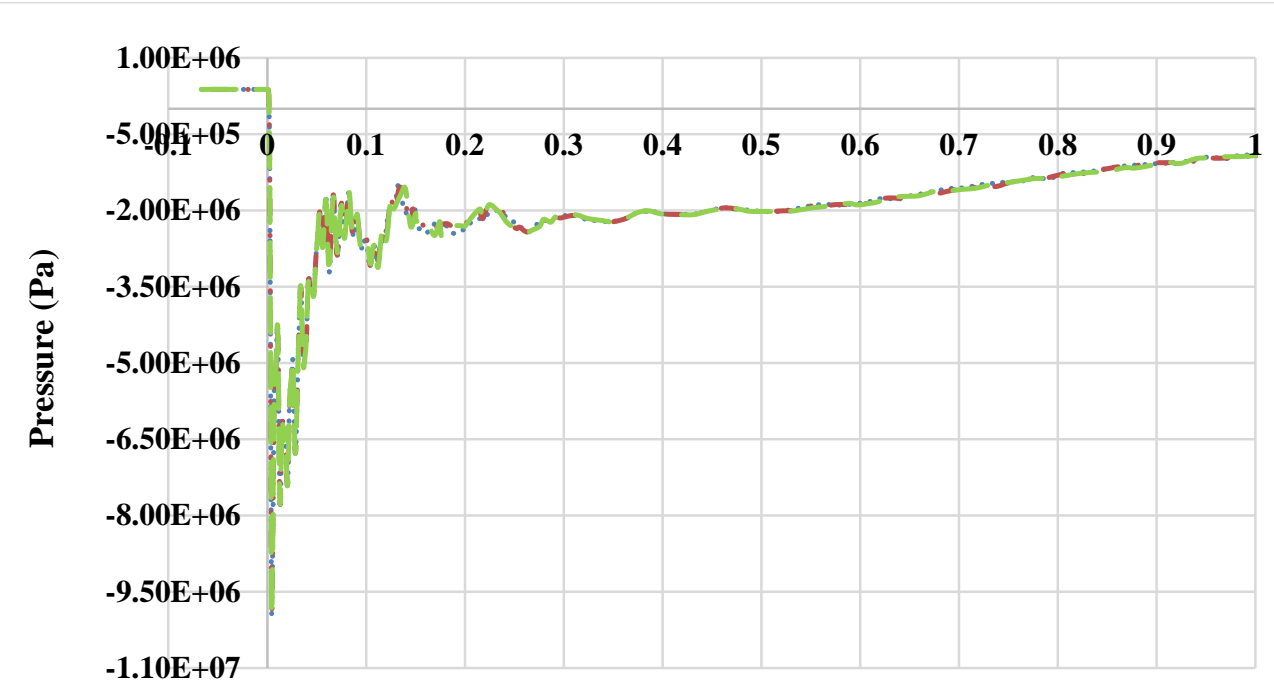

Time (s)

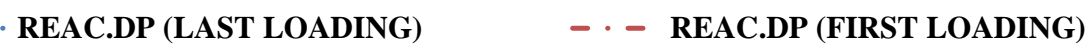

— REAC.DP (constant power)

Fig. (7): Variation of The Reactor Pressure after the emergency in the three cases of study

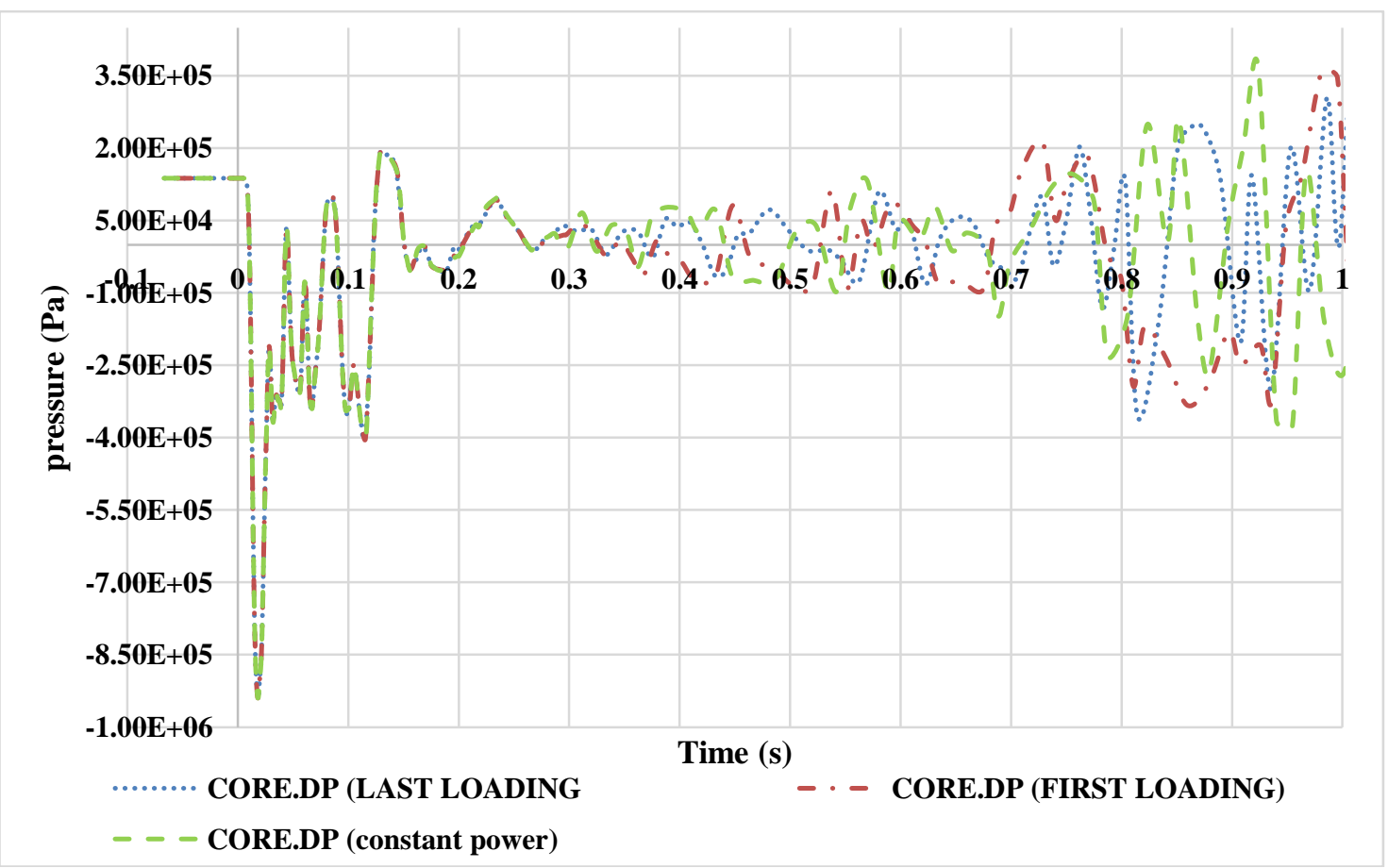

Fig. (8): The Reactor core Pressure Drop after the emergence in the three cases of study 


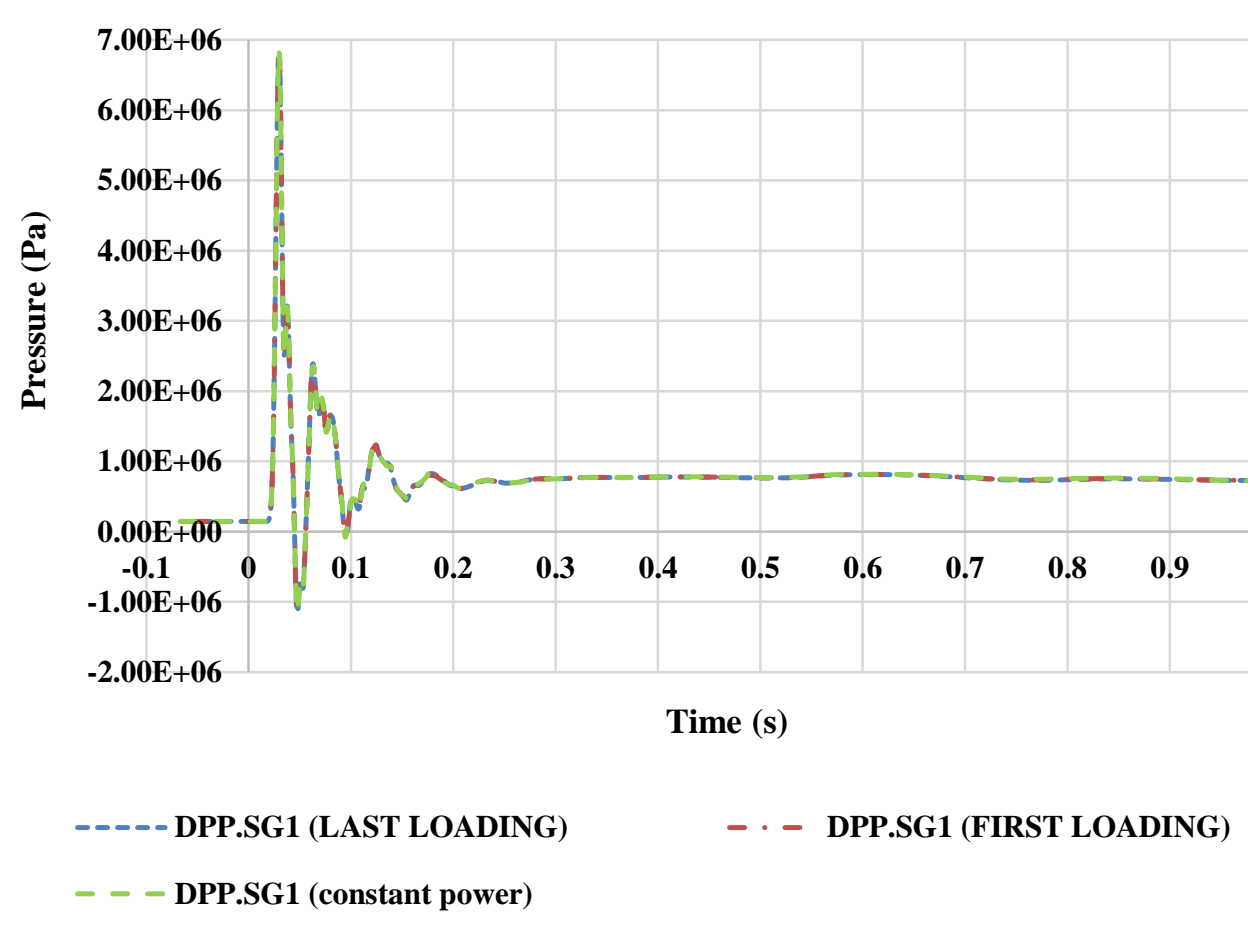

Fig. (9): The Steam generator Pressure Difference after the emergency in the three cases of study

\section{Conclusion}

It is observed that the strongest amplitude and frequency of pressure waves fluctuations in NPP elements occurred during the first seconds of accident initiation, thus in the present work the analysis is focused on this period .These pressure fluctuations can lead to significant dynamic loads on the structural elements of the NPP. It is shown that the power changes have no practical effect on the hydrodynamics behavior of the process during the considered time interval. For the future work, it is recommended to analyze the dynamic loads on the structural elements of the concerned reactor components.

\section{ACKNOWLEDGEMENT}

This research was supported by National Research Nuclear University MEPhI (Moscow Engineering Physics Institute).

\section{Reference}

1. PNAE G-1-036-95 (NP-006-98). Requirements for the content of the report on the safety justification of the NPP with a VVER-type reactor (with Change No. 1 of 20.12.2005).

2. Dina Ali Amer, Nikonov S.P., LOCA and Pressure waves in the first loop of the VVER-
1000 Reactor, 28th Symposium of AER on VVER Reactor Physics and Reactor Safety, Olomouc, Czechia, October 8-12, 2018

3. Dina Ali Amer, Nikonov S.P., Analysis for pressure waves in VVER-1000 due to LOCA in different locations, XXI international conference of young specialists in nuclear power plants, JSC OKB GIDROPRESS, Podolsk, April 10-11, 2019

4. Dina Ali Amer, Nikonov S.P., Instantaneous emergency situations in VVER-1000 and their consequences, International youth scientific school-conference "Modern problems of physics and technology", Moscow, MEPhI, April 16-18, 2019.

5. Dina Ali Amer, Nikonov S.P., Travleev A., The first circuit of VVER-1000 and the most dangerous places of LBLOCA as a source of dynamic load on the equipment, 11 MHTK "Ensuring the safety of nuclear power plants with VVER "OKB " GIDROPRESS", Podolsk, Russia 21-24 may 2019

6. Dina Ali Amer, Nikonov S.P., Analysis of uncertainty in the concept of "instantaneous" in the calculation of emergency modes, AtomFuture-2018, Obninsk, November 2018 
7. Dina Ali Amer, Nikonov S.P., Emergency Situations and Pressure Waves in VVER-1000, 6-th Conference on Radiation sciences and applications, Ibis Dahab, Egypt, October 2226, 2018

8. Dina Ali Amer, Nikonov S.P. Pressure Waves In The Primary Circuit Of The VVER - 1000 Reactor At Instant Stop Of The MCP, ICNRP Volga-2018, International conference for young scientists, specialists and post-graduates on Nuclear Reactor Physics, September, 2018., IOP Conf. Series: Journal of Physics: Conf. Series 1133 (2018) 012049 doi :10.1088/17426596/1133/1/012049

9. V. A. Tereshonok, S.P. Nikonov, M. P. Lizorkin, K. Velkov, A. Pautz, K. Ivanov, International Benchmark for Coupled Codes and Uncertainty Analysis in Modelling: Switching-off of one of the four operating main circulation pumps at nominal power at NPP Kalinin unit, 18th Symposium of AER on VVER Reactor Physics and Reactor Safety, Hungary, Eger, Oct. 6-10,2008

10. H. Austregesilo, H. Deitenbeck, A. Langenfeld, J. Scheuer, P. Schöffel, ATHLET 3.1A, Programmer's Manual, March 2017

11. Computer Code AC2, Code Certificate N0 1701, Software License Agreement N0.L/M-03, 11 Sep. 2017
12. Rostekhnadzor, FBU "STC NRS", Certification Passport of the Software tool no. 350 dated 17.04.2014

13. Dina Ali Amer, Nikonov S.P., Comparing the Consequences Pressure Waves due to MCP pump stops and LOCA in VVER-1000, "Vestnik natsional'nogo issledovatel'skogo yadernogo universiteta”, 2019, volume 8, № 4, P. 309-320

14. ATHLET, Mod 3.0 Cycle A, User's Manual. Part 2: ATHLET Input Data Description.

15. V. A. Tereshonok, S.P. Nikonov, M. P. Lizorkin, K. Velkov, A. Pautz, K. Ivanov, International Benchmark for Coupled Codes and Uncertainty Analysis in Modelling: Switching-off of one of the four operating main circulation pumps at nominal power at NPP KALININ UNIT 3, 18th Symposium of AER on VVER Reactor Physics and Reactor Safety, Hungary, Eger, Oct. 6-10, 2008

16. S.Nikonov, Lizorkin M., V.Tereshonok, K.Velkov ,A. Pautz, OECD Benchmark on Measured Data at NPP Kalinin Unit 3 and GRS/KI Results by the Coupled System Code ATHLET/BIPR-VVER, Annual Meeting on Nuclear Technology, May 12-14, JT 2009, Dresden, Germany 